\title{
Surgical management of lung gangrene
}

\author{
Baiya Krishnadasan $M D^{1}$, Vandy $L$ Sherbin $M D^{2}$, Eric Vallières $M D^{1}$, Riyad Karmy-Jones $M D^{1}$ \\ ${ }^{1}$ Divisions of Cardio-Thoracic Surgery and ${ }^{2}$ Pulmonary Medicine, University of Washington, \\ Seattle, Washington, USA
}

B Krishnadasan, VL Sherbin, E Vallières, R KarmyJones. Surgical management of lung gangrene. Can Respir J 2000;7(5):401-404.

OBJECTIVE: To review the outcomes of five cases of pulmonary resection for lung gangrene.

DESIGN: A retrospective chart review.

SETTING: A tertiary referral centre.

POPULATION STUDIED: Five patients who underwent pulmonary resection for lung gangrene between April and December 1999.

MAIN RESULTS: Pathological confirmation of lung gangrene was obtained in all cases. Three patients were ventilator dependent. All five patients had ongoing sepsis despite antibiotic therapy. Additional indications for resection included bronchopleural fistula (two patients), empyema (three patients) and hemoptysis (one patient). In two cases, there was evidence of bilateral, diffuse necrotizing pneumonia, while in three cases the process was localized to one side. Computed tomography revealed cavitation in four cases and the absence of blood supply to the affected lung in one case. Surgical resection included wedge resection (one patient), lobectomy (two patients), bilobectomy (one patient) and pneumonectomy (one patient). In all cases, the bronchial stump was reinforced with an intercostal flap. Postoperative empyema occurred in two cases, one treated by thoracoscopic decortication, the other by percutaneous drainage. There were no instances of stump leak and no deaths. One patient remains ventilator dependent. CONCLUSIONS: Resection for lung gangrene is possible even in the setting of diffuse parenchymal changes and ventilator dependency. A computed tomography scan of the chest is important to make the diagnosis of lung gangrene and to plan operative management. Reinforcement of the bronchial stump is critical.

\section{Traitement chirurgical de la gangrène pul- monaire}

OBJECTIF : Passer en revue l'issue de cinq cas de résection pour gangrène pulmonaire.

MODÈLE : Analyse rétrospective des dossiers.

CONTEXTE : Centre de soins tertiaires.

POPULATION ÉTUDIÉE : Cinq patients qui ont subi une résection pulmonaire pour gangrène entre avril et décembre 1999.

PRINCIPAUX RÉSULTATS : Une confirmation anatomopathologique de la gangrène pulmonaire a été obtenue dans tous les cas. Trois patients dépendaient de ventilateurs. Les cinq patients présentaient une septicémie, malgré l'administration d'antibiotiques. Les autres indications de la résection étaient, entre autres, une fistule bronchopleurale (deux patients), l'empyème (trois patients) et l'hémoptysie (un patient). Dans deux cas, on a noté des signes de pneumonie nécrosante bilatérale diffuse, alors que dans trois cas, le processus était localisé à un seul côté. La tomodensitométrie a révélé la présence de cavitations dans quatre cas et l'absence d'irrigation sanguine au poumon affecté dans un cas. La résection chirurgicale a inclus une résection cunéiforme (un patient), une lobectomie (deux patients), une bilobectomie (un patient) et une pneumonectomie (un patient). Dans tous les cas, le moignon bronchique a été consolidé par un lambeau intercostal. L'empyème postopératoire est survenu dans deux cas, l'un traité par décortication thoracoscopique, l'autre par drainage percutané. On n'a noté aucun cas de fuite au niveau du moignon, ni décès. Un patient est resté dépendant du ventilateur.

CONCLUSION : La résection pour gangrène pulmonaire est possible, même dans le contexte d'anomalies parenchymateuses diffuses et de dépendance à l'endroit du ventilateur. La tomodensitométrie pulmonaire est importante pour poser le diagnostic de gangrène pulmonaire et pour planifier le traitement opératoire. La consolidation du moignon bronchique est cruciale.

Key Words: Lung gangrene; Necrotizing pneumonia

Correspondence and reprints: Dr Riyad Karmy-Jones, Division of Thoracic Surgery, University of Washington Medical Center, Box 356310, 1959 NE Pacific Street, Seattle, Washington 98195, USA. Telephone 206-731-2857 or 206-543-3093, fax 206-731-3656 or 206-543-0325, e-mail karmy@u.washington.edu 
$\mathrm{G}$ angrene of the lung is an uncommon complication of bacterial pneumonia that develops as the inflammatory process moves centrally, leading to the obstruction of both bronchial and pulmonary blood supplies to the affected segment. In conjunction with the obstruction of the proximal bronchus, this leads to failure of antibiotics to reach the involved segment, progressive destruction and loss of architecture, sepsis, and possibly the development of bronchopleural fistula and life-threatening hemoptysis. Computed tomography (CT) is useful in detecting the development of gangrene and predicting the failure of both interventional techniques and medical therapy (1). The surgical management and outcome are affected by the extent of underlying destruction and the patient's overall condition. We present our experience with lung resection for pulmonary gangrene to illustrate both the usefulness of chest CT in making the diagnosis and the success of resection, emphasizing the importance of reinforcing bronchial closure with viable tissue.

\section{PATIENTS AND METHODS}

Clinical features: Five patients admitted to Harborview Medical Center, a community level I trauma centre affiliated with the University of Washington Medical Center, Seattle, Washington, between April and December 1999 underwent resection for lung gangrene. Pulmonary gangrene was defined by the presence of sepsis (fever, positive sputum and blood cultures, elevated leukocyte count) and a CT scan demonstrating at least one of the following: no perfusion to one lobe or more, occlusion of bronchus with necrotic debris and/or CT evidence of central necrosis. The diagnosis of lung gangrene was confirmed by pathological review.

Patients: The patients (two female, three male) ranged from

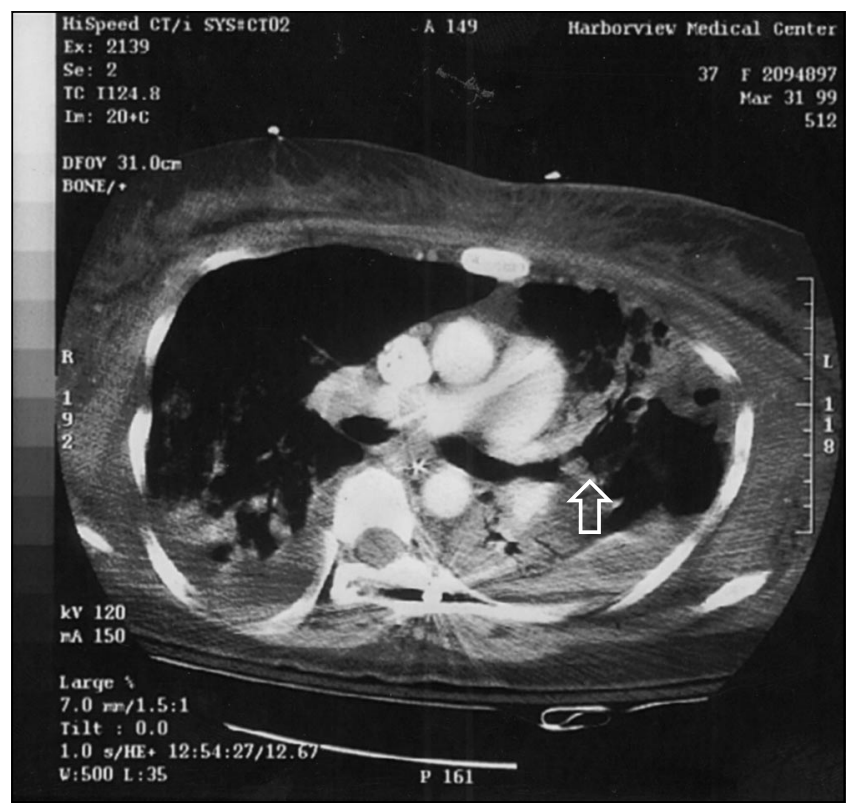

Figure 1) Computed tomography scan of a patient with respiratory failure. The scan demonstrates a cavity in the left upper lobe with evidence of bronchopleural fistula (arrow). The findings were confirmed at surgery, and the patient was successfully weaned from the ventilator
36 to 56 years of age. The etiology was community-acquired pneumonia in four patients and hospital-acquired pneumonia as a complication of blunt chest trauma in one patient. Three patients had long-standing histories of intravenous drug and alcohol abuse. In addition, one patient was HIV-positive and a second had documented hepatitis B with cirrhosis (Child's classification B) and esophageal varices. Sputum cultures were positive in all cases: Streptococcus pneumoniae (four patients) and Psuedomonas aeruginosa (one patient). Blood cultures were positive for $S$ pneumoniae in two cases.

Interventions: At the time of surgical consultation, patients had been treated for two to eight weeks. Three patients had been treated with chest tubes for presumed empyema and antibiotics based on sputum and blood cultures. Three patients were ventilator dependent, and one had been extubated the day before the consultation. The primary indications for surgical consultation were persistent sepsis in four patients (two with positive blood cultures), two of whom also had bronchopleural fistulae (Figures 1 to 3 ). One of the latter patients had evidence of air trapping and was unable to be oxygenated despite permissive hypercapnia (Figure 1). One patient was referred primarily because of hemoptysis.

Pulmonary gangrene involved the left upper lobe in two cases (both with diffuse, bilateral parenchymal consolidation consistent with necrotizing pneumonia), peripheral right upper lobe in one, right middle and lower lobes in one, and the entire right lung in one (all three patients with unilateral right lung changes were consistent with necrotizing pneumonia). Cavitary changes were noted in four patients, while in one patient who presented with hemoptysis, the CT scan demonstrated a loss of vascular supply to the right middle and lower lobes. Cavitary changes were seen in one patient

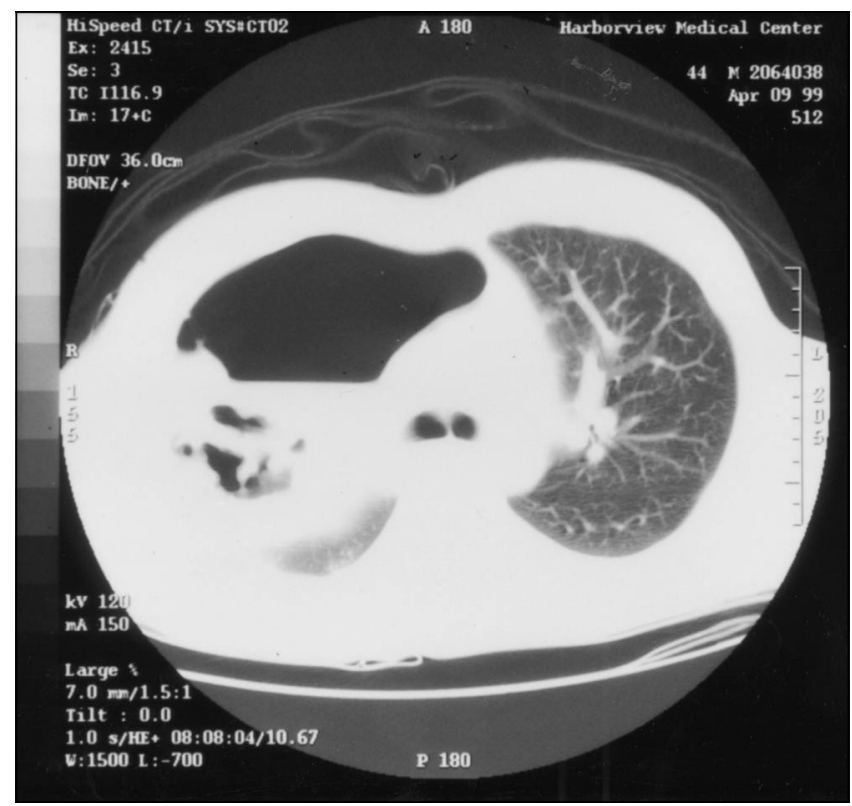

Figure 2) Cavitary changes with hydropneumothorax in a patient with a history of poor dental hygiene and a previous chest $x$-ray demonstrating patchy, bilateral upper lobe pneumonia 


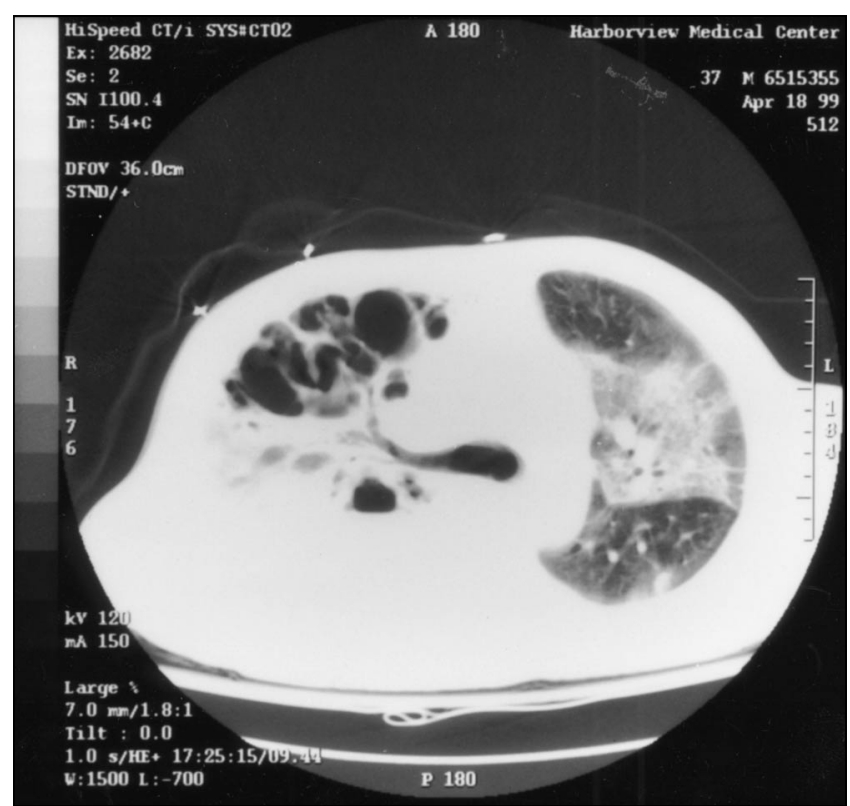

Figure 3) Computed tomography scan of an HIV-positive patient with basal fluid collection and persistent fever. At surgery, pneumonectomy was required for extensive upper and lower lobe gangrene

before obtaining the CT scan, while plain radiography identified hydropneumothorax in a second patient. The remaining radiographs identified only parenchymal consolidation consistent with pneumonia.

During surgery, a single-lumen endotracheal tube was required in three patients because of the patient's inability to tolerate single lung anesthesia. Procedures included left upper lobectomy (two cases), right upper wedge (one case), right middle and lower lobectomy (one case), and right pneumonectomy (one case). In all cases, the bronchial stump was reinforced with an intercostal muscle flap. An irrigation system similar to one described previously (2), instilling $100 \mathrm{~mL} / \mathrm{h}$ of normal saline until effluent was clear, was used in two cases. Pathology confirmed gangrene arising in a lung affected by extensive pneumonia in all cases.

\section{RESULTS}

Two patients developed postoperative empyema (both after left upper lobectomy); one was treated by thoracoscopic decortication, the other by percutaneous drainage. Neither of these patients had received 'adjuvant' therapy with an irrigation system. The patients' length of stay varied from 10 days to three months, but all patients were off the ventilator and living independently at the time of review.

\section{DISCUSSION}

Pulmonary gangrene is an uncommon complication of bacterial pneumonia but one that has been reported in both seemingly immune-competent and immune-compromised patients (3-8). It is often grouped with necrotizing pneumo-

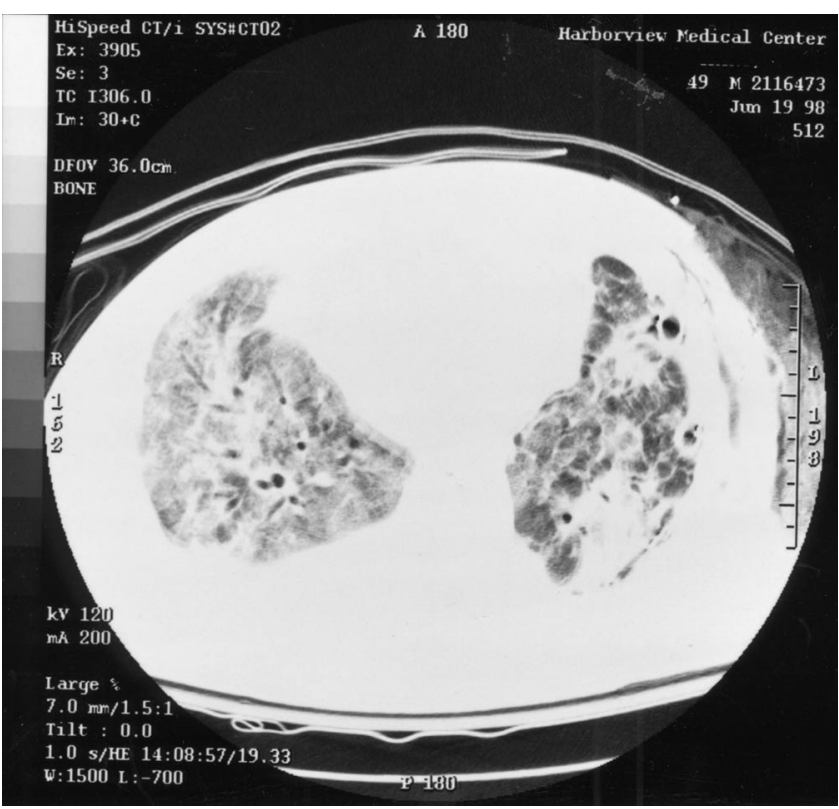

Figure 4) Diffuse, patchy inflammatory changes in a patient with bilateral, necrotizing pneumonia. The early picture is similar to typical adult respiratory distress syndrome but, in the setting of positive sputum and blood cultures and small cavities, is consistent with necrotizing pneumonia. There is no evidence of focal gangrene or large abscess

nia and lung abscess but has features that make it a distinct entity. Necrotizing pneumonia is characterized by a consolidated lung with peripheral necrosis. Typically, multiple small cavities less than $1 \mathrm{~cm}$ in diameter are noted. The parenchymal inflammation involves one or multiple lobes, and the reported $20 \%$ mortality rate depends upon the extent of underlying disease $(9,10)$ (Figure 4). Complications of necrotizing pneumonia include abscess formation and frank gangrene. Gangrene is distinguished by the development of central vascular obstruction, obstruction of the bronchus and, usually, significant cavitation. These features, which are detected by chest CT, predict the failure of medical management (1). CT can also detect the development of peripheral bronchopleural fistulae (11). Interestingly, $S$ pneumoniae is increasingly reported as a cause of both necrotizing pneumonia and lung gangrene $(3,8,12,13)$.

Surgery is required in the majority of cases $(3-8,14,15)$. As previously noted, the loss of blood supply and obstruction of the bronchus prevent both the delivery of antibiotics and the expectoration of necrotic material $(1,6)$. Percutaneous drainage can be attempted but appears to be associated with higher failure rates and increased complications in cases of necrotizing pneumonia (16). Surgical outcomes are determined by the extent of the underlying disease and the patient's overall condition. Lesnitskii et al (14) described a 'diffuse' form of lung gangrene with an overall mortality of nearly $40 \%$ and a 'localized' form with a mortality of nearly $17 \%$. Patients who are critically ill may be managed by procedures directed primarily at draining empyema (fenestration), followed by interval lung resection when they stabilize (3-6,15). In the majority of cases, lobectomy or pneumonectomy is required. Although there are no data regarding the value of stump rein- 
forcement in this specific setting, our bias is similar to other authors in providing some additional stump coverage (4-7). The risk of bronchial stump leak, especially in patients who have high airway pressures, may be increased due to either inflammatory changes involving the stump or residual empyema eroding the stump. One option, which we have not yet used ourselves, might be to use muscle flaps or omentum to fill the potential empyema cavity and reinforce the bronchial closure.

Our results are consistent with the concept that CT of the

\section{REFERENCES}

1. Curry CA, Fishman EK, Buckley JA. Pulmonary gangrene: radiological and pathologic correlation. South Med J 1998;91:957-60.

2. Karmy-Jones R, Sorenson V, Horst HM, Lewis JW Jr, Rubinfeld I. Rigid thorascopic debridement and continuous pleural irrigation in the management of empyema. Chest 1997;111:272-4.

3. Hammond JM, Lyddell C, Potgieter PD, Odell J. Severe pneumococcal pneumonia complicated by massive pulmonary gangrene. Chest 1993;104:1610-2.

4. Juettner FM, Arian-Schad K, Kraus I, Gallhofer G, Popper H, Friehs G. Total unilateral lung gangrene in Hodgkin's disease: treatment by thoracostomy. Ann Thorac Surg 1991;51:302-3.

5. Refaely Y, Weissberg D. Gangrene of the lung: treatment in two stages. Ann Thorac Surg 1997;64:970-4.

6. Phillips LG, Rao KV. Gangrene of the lung. J Thorac Cardiovasc Surg 1989;97:114-8.

7. Penner C, Maycher B, Long R. Pulmonary gangrene. A complication of bacterial pneumonia. Chest 1994;105:567-73.

8. Collazos J, Fernandez A, Mayo J, Martinez E. Pulmonary gangrene secondary to pneumococcal pneumonia in a patient with AIDS. Clin Infect Dis 1997;24:268-9. chest can identify pulmonary gangrene in patients with persistent pulmonary sepsis. Furthermore, resection can be performed even in the setting of high ventilator requirements with acceptable results. Patients may not tolerate single lung ventilation, which increases the technical difficulty. Bronchial stumps must be reinforced. Patients with residual spaces may benefit from routine irrigation of the cavity postoperatively. The residual space is at risk of postoperative empyema; strategies such as pleural irrigation should be considered for its prevention or treatment.

9. Disler D, Deluca SA. Necrotizing aspiration pneumonia. Am Fam Physician 1991;44:1719-21.

10. Johanson WG Jr, Harris GD. Aspiration pneumonia, anaerobic infections, and lung abscess. Med Clin North Am 1980;64:385-94.

11. Westcott JL, Volpe JP. Peripheral bronchopleural fistula: CT evaluation in 20 patients with pneumonia, empyema, or postoperative air leak. Radiology 1995;196:175-81.

12. Isaacs RD. Necrotizing pneumonia in bacteraemic pneumococcal infection. Br J Dis Chest 1986;80:295-6.

13. Kerem E, Bar Ziv Y, Rudenski B, Katz S, Kleid D, Branski D. Bacteremic necrotizing pneumococcal pneumonia in children. Am J Respir Crit Care Med 1994;149:242-4.

14. Lesnitskii LS, Kostiuchenko AL, Tulupov AN. [Several problems of pathogenesis and treatment of pulmonary gangrene]. Grudn Khir 1989;4:39-44.

15. Rudin EP, Bogdanov AV, Chernyshev VS, Zemskov EV. [Surgical choices in the treatment of lung gangrene]. Grud Serdechnososudistaia Khir 1990;4:45-7.

16. Hoffer FA, Bloom DA, Colin AA, Fishman SJ. Lung abscess versus necrotizing pneumonia: implications for interventional therapy. Pediatr Radiol 1999;29:87-91. 


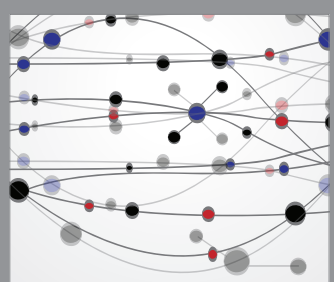

The Scientific World Journal
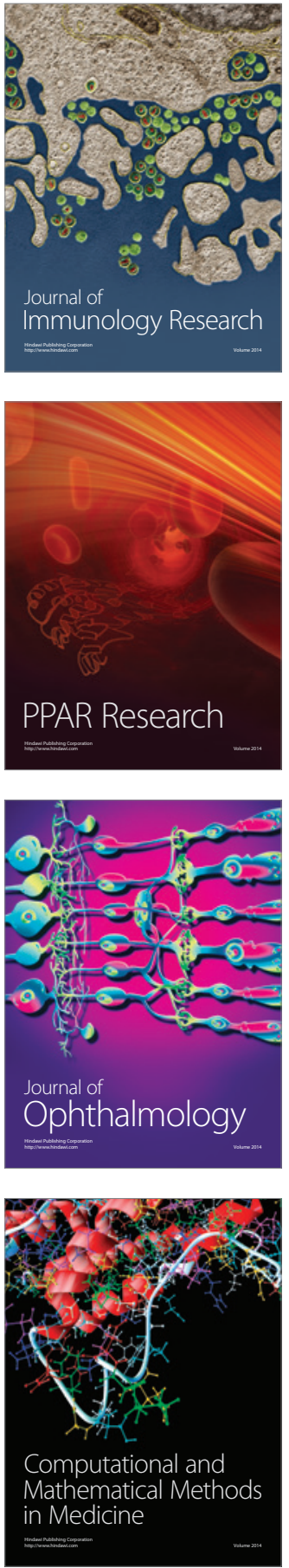

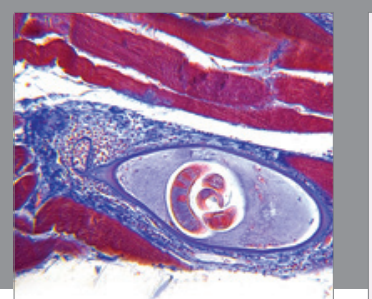

Gastroenterology Research and Practice

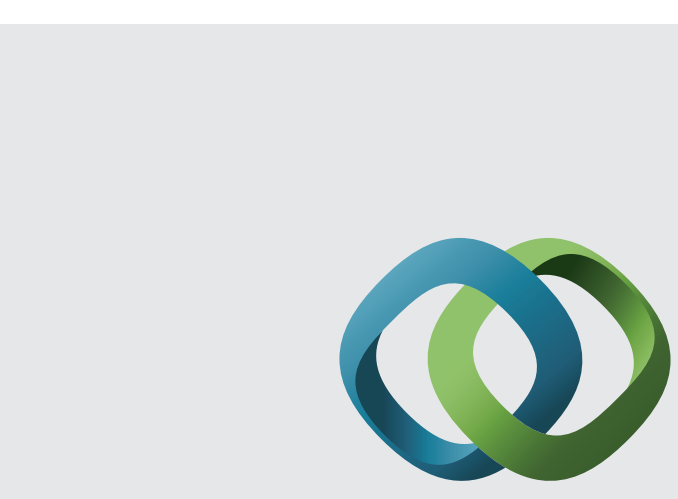

\section{Hindawi}

Submit your manuscripts at

http://www.hindawi.com
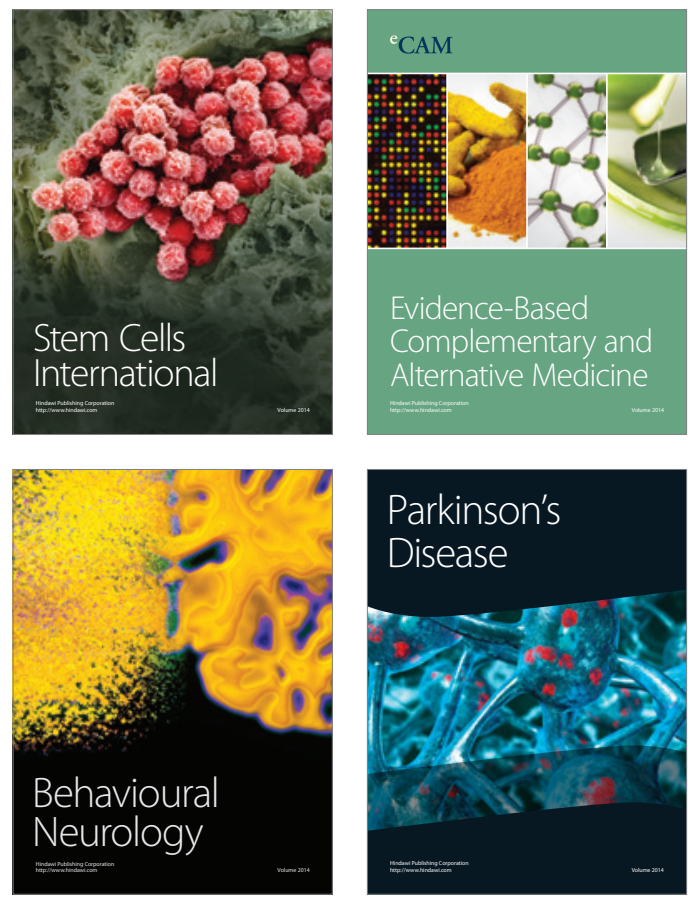
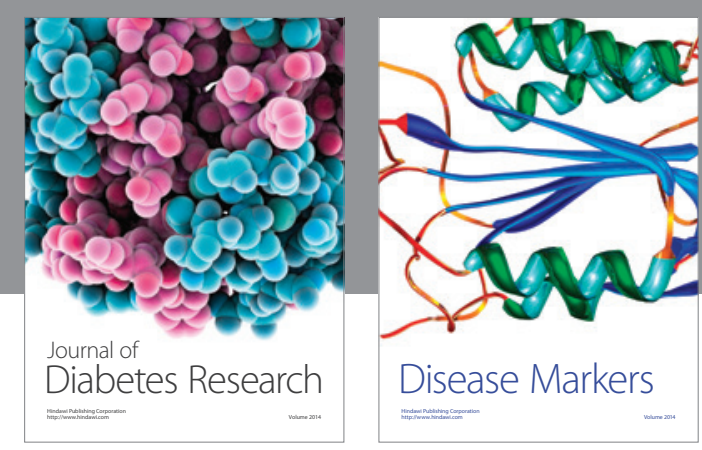

Disease Markers
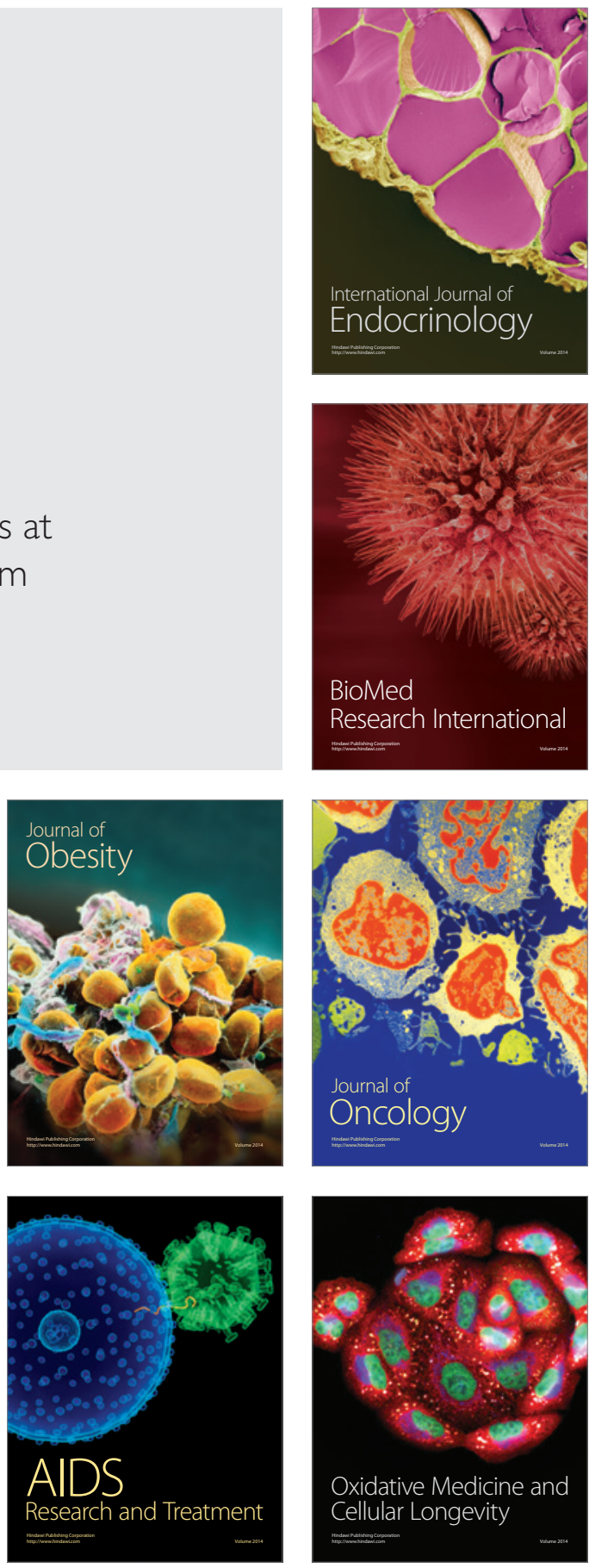